\title{
Penfigoide bolhoso no adulto mais jovem: relato de três casos
} Bullous pemphigoid in younger adults: three case reports

\author{
Roberta Richter Zanella ${ }^{1}$ \\ Antônio José Tebcherani ${ }^{2}$ \\ Ana Paula Galli Sanchez ${ }^{4}$
}

\author{
Tamar Alencar Xavier ${ }^{1}$ \\ Valéria Aoki ${ }^{3}$
}

\begin{abstract}
Bullous pemphigoid is an autoimmune subepidermal bullous dermatosis more commonly observed in the elderly (over 70 years old). Autoantibodies are produced for specific antigens of the epidermal basement membrane zone: BP 180 and BP 230 (hemidesmosome proteins). We report three cases of bullous pemphigoid in adults younger than 50 years old, discussing the clinical characteristics of the disease in younger patients.

Keywords: Pemphigoid, bullous; Skin diseases, vesiculobullous; Young adult

Resumo: O penfigoide bolhoso é uma dermatose bolhosa autoimune subepidérmica, mais comumente observada na população idosa (acima dos 70 anos). Autoanticorpos são formados contra antígenos específicos da zona de membrana basal: BP180 e BP230 (proteínas do hemidesmossomo). Apresentamos três casos de penfigoide bolhoso, em adultos com menos de 50 anos de idade, destacando as peculiaridades clínicas na faixa etária mais jovem.

Palavras-chave: Adulto jovem; Dermatopatias vesiculobolhosas; Penfigoide bolhoso
\end{abstract}

\section{INTRODUCTION}

Bullous pemphigoid (BP) is an autoimmune subepidermal dermatosis that generally affects people older than 70 years, with no ethnic, racial or sexual predilection. ${ }^{1,2,3}$ Lesions occur mostly along large skin folds and on the abdomen and may initially appear as urticarial and itchy lesions, with blisters eventually erupting. These are located on erythematous, erythematous-edematous or apparently healthy skin. They are tense and their content is serohemorrhagic. Mucous membranes are affected in $10-35 \%$ of the cases. ${ }^{2,3}$

The following clinical variants are described: classic (described above), localized, nodular, vegetating, erosive, erythrodermic, juvenile and druginduced. ${ }^{1,2,3}$

Reported cases of BP in patients under 60 years old are rare. ${ }^{1,4}$ We report three cases of BP in adults younger than 50 years, with different clinical characteristics and evolution.

\section{CASE REPORTS}

Case 1

A 37-year-old mixed-raced (pardo) female patient, presenting with itching associated with blisters and urticarial lesions, which had been present for twenty days. The blisters with serous content were located on erythematous or apparently healthy skin on the neck, trunk and limbs, with a preference for the large skin folds (Figure 1). There were no mucosal lesions or overall poor health. The patient denied use of medication. Eosinophil count of $64 \%$ and elevated IgE. Anatomopathological examination (AP) of a bullous lesion showed subepidermal cleavage with a mixed inflammatory infiltrate (polymorphonuclear cells and lymphocytes) (Figure 2). Direct immunofluorescence (DIF) of perilesional skin showed linear, continuous and intense deposition of $\mathrm{C} 3$ in the basal membrane zone (BMZ) (Figure 3). Once BP was diagnosed, we initiated treatment with dapsone (100mg/day) and prednisone $(0.5 \mathrm{mg} / \mathrm{kg})$, with resolution of the cutaneous condition in three weeks.

Received on 11.02.2010.

Approved by the Advisory Board and accepted for publication on 28.03.2010.

* Study conducted at the Dermatology Service of Complexo Hospitalar Padre Bento de Guarulhos - Guarulhos (SP), Brazil.

Conflict of interest: None / Conflito de interesse: Nenbum

Financial funding: None / Suporte financeiro: Nenbum

Post-graduation - Physician specializing in Dermatology, Complexo Hospitalar Padre Bento de Guarulhos - Guarulhos (SP), Brazil.

MSc in Anatomic Pathology, Federal University of Sao Paulo (UNIFESP) - Pathologist at the Dermatology Service, Complexo Hospitalar Padre Bento de Guarulhos - Guarulhos (SP), Brazil.

$\mathrm{PhD}$ in Health Sciences, Medicine College of the University of Sao Paulo (FMUSP) - PhD professor at the Department of Dermatology of the Clinics Hospital, Medicine College of the University of Sao Paulo ( HC - FMUSP) - Sao Paulo (SP), Brazil.

MSc in Health Sciences, Medicine College of the University of Sao Paulo (FMUSP) - Assistant physician at the Dermatology Service, Complexo Hospitalar Padre Bento de Guarulhos - Guarulhos (SP), Brazil. 


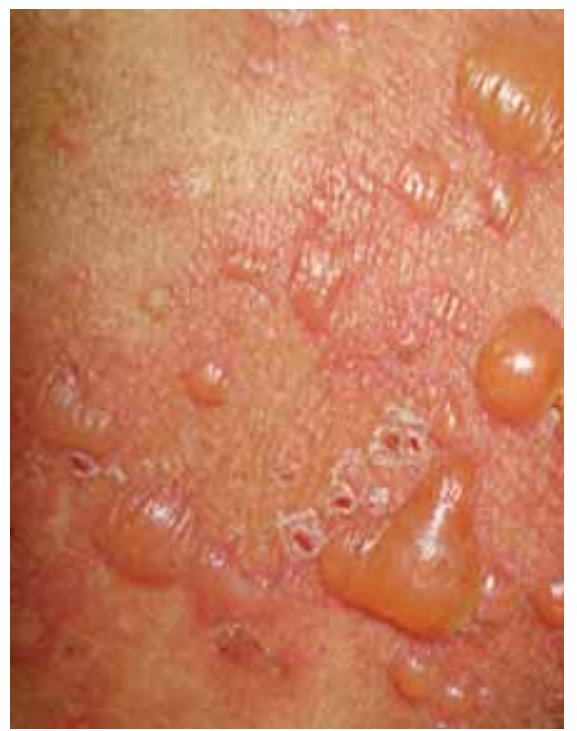

Figure 1: Large, tense blisters with serous content located on erythematous or apparently healthy skin

Source: Clinical manifestations of bullous pemphigoid

\section{Case 2}

A forty-nine white female patient reported having had intense itching for sixty days and appearance of widespread erythematous plaques fifteen days ago, with subsequent evolution to large, tense, serohemorrhagic blisters on an erythematous base on the head, neck, trunk and limbs (Figures 4 and 5). She presented with ulcers in the nasal, oral and genital mucosa and overall poor health, being promptly admitted. Relevant medical history: hypertension, heart failure and mitral valvuloplasty. The patient used losartan potassium and presented eosinophil count of 32\% and elevated IgE. AP examination of the bullous lesion showed subepidermal cleavage with inflammatory infiltrate rich in eosinophils and neutrophils at the bottom of the blister. DIF of perilesional skin showed

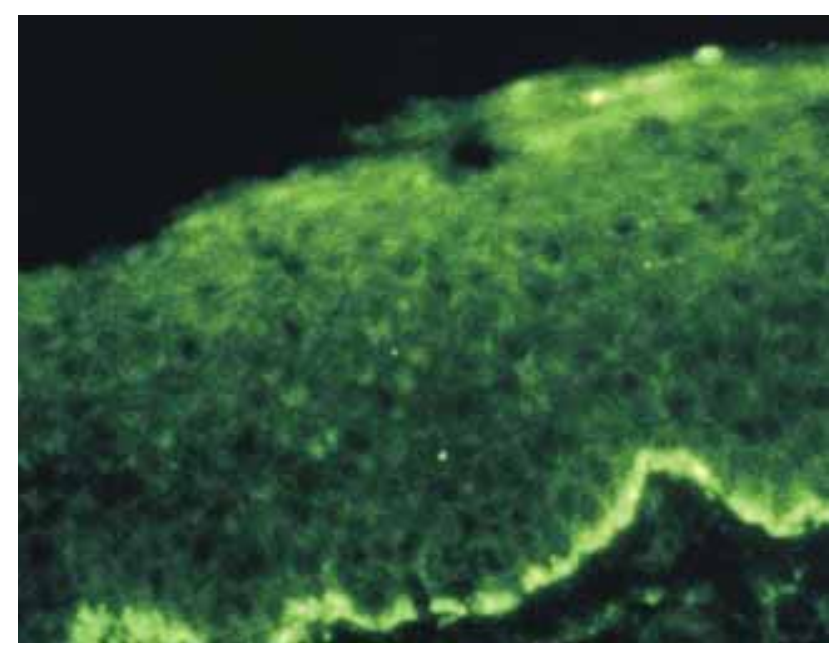

Figure 3: Linear, continuous and intense deposition of C3 in basal membrane zone. Direct immunofluorescence

linear, continuous and intense deposition of $\operatorname{IgG}$ and $\mathrm{C} 3$ in the BMZ. Once BP was diagnosed, losartan was discontinued and dapsone $(100 \mathrm{mg} /$ day $)$ and prednisone $(0.5 \mathrm{mg} / \mathrm{kg} / \mathrm{day})$ were introduced. The patient evolved with worsening of the skin condition and overall health in the first week of treatment, and the prednisone dose was increased to $1 \mathrm{mg} / \mathrm{Kg} / \mathrm{day}$. The patient was transferred to the intensive care unit, where she received intravenous gammaglobulin. Despite improvement of the cutaneous condition, she died from sepsis one month after initiation of therapy.

\section{Case 3}

A forty-three-year-old mixed-raced (pardo) female patient reported having had intense itching

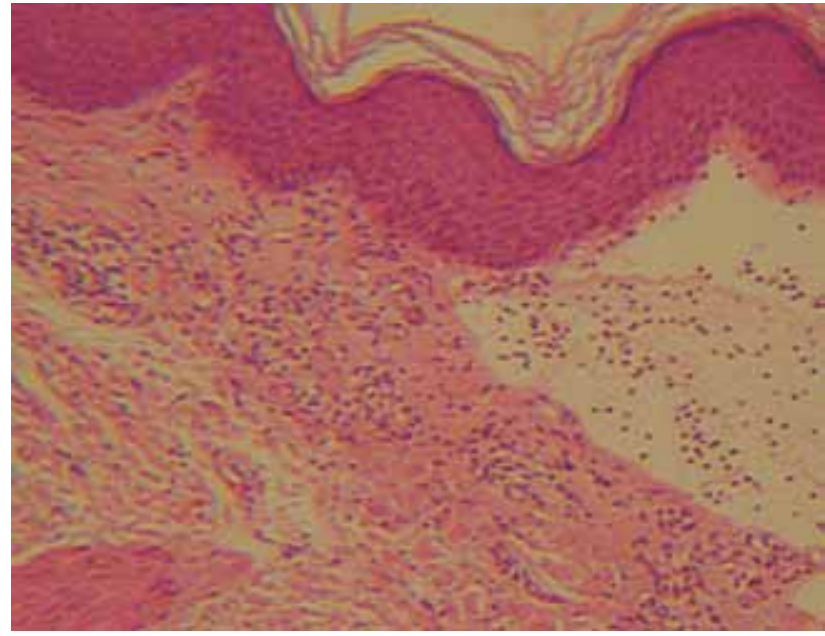

FIGURE 2: Subepidermal cleavage with infiltrate of polymorphonuclear cells and lymphocytes (HE 200x). Anatomopathological examination of a bulla

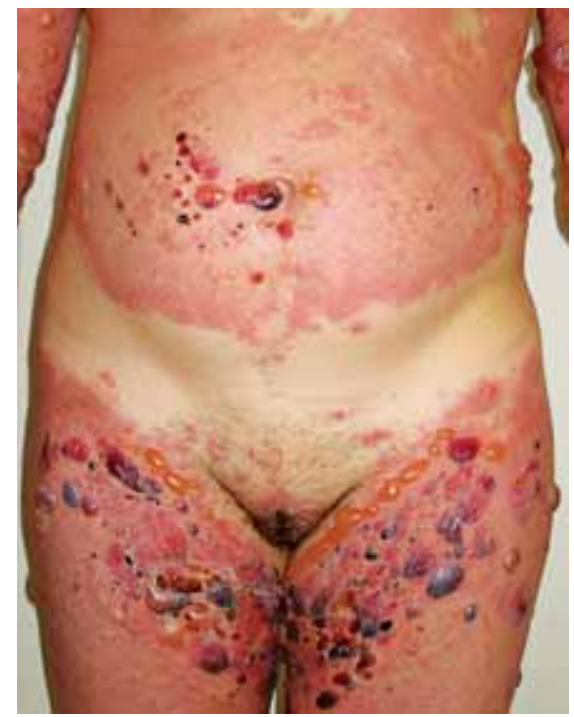

Figure 4:

Predominant ery-

thematous component with urticariform lesions at the onset of the disease. Notice the areas preferably affected by the first bullous lesions; large skin folds.

Source: Clinical manifestations of bullous pemphigoid 


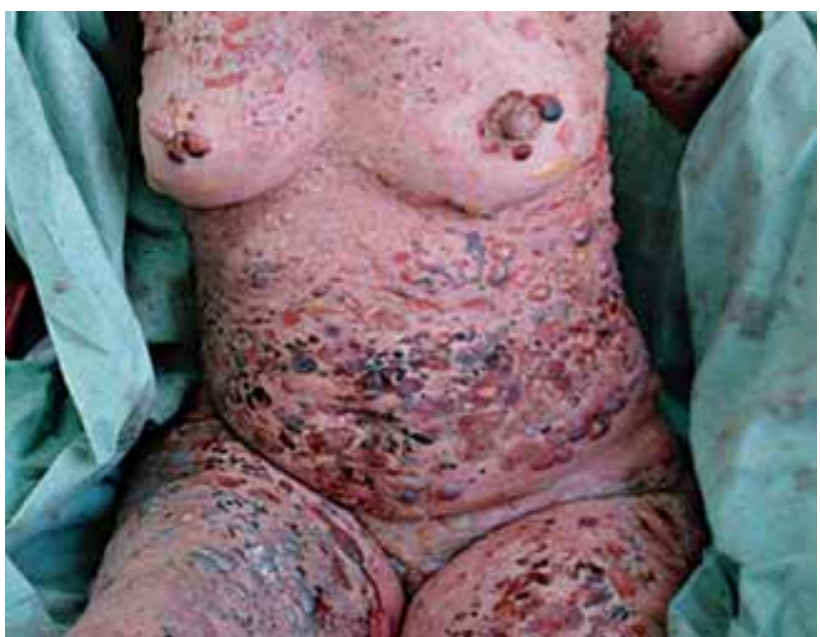

FIGURE 5: Evolution with dissemination of large, tense, serohemorrhagic blisters on erythematous skin. Notice that the neck has also been affected.

Source: Clinical manifestations of bullous pemphigoid

associated with the onset of urticarial plaques, bullae, papular and nodular lesions. The bullae, with serous and hemorrhagic content, were located on apparently healthy or erythematous skin on the neck, trunk and limbs. The limbs also showed papular, nodular lesions and lichenified plaques (Figure 6). On some of these lesions, bullae could be observed. She had no mucosal lesions or overall poor health. The patient reported hypertension and was under treatment with captopril. The AP examination of the bullous lesion showed subepidermal cleavage with inflammatory infiltrate rich in polymorphonuclear cells. The AP examination of the papular lesion revealed hyperkeratosis, acanthosis, dermal fibrosis and superficial perivascular mononuclear infiltrate. DIF of perilesional skin (bulla)

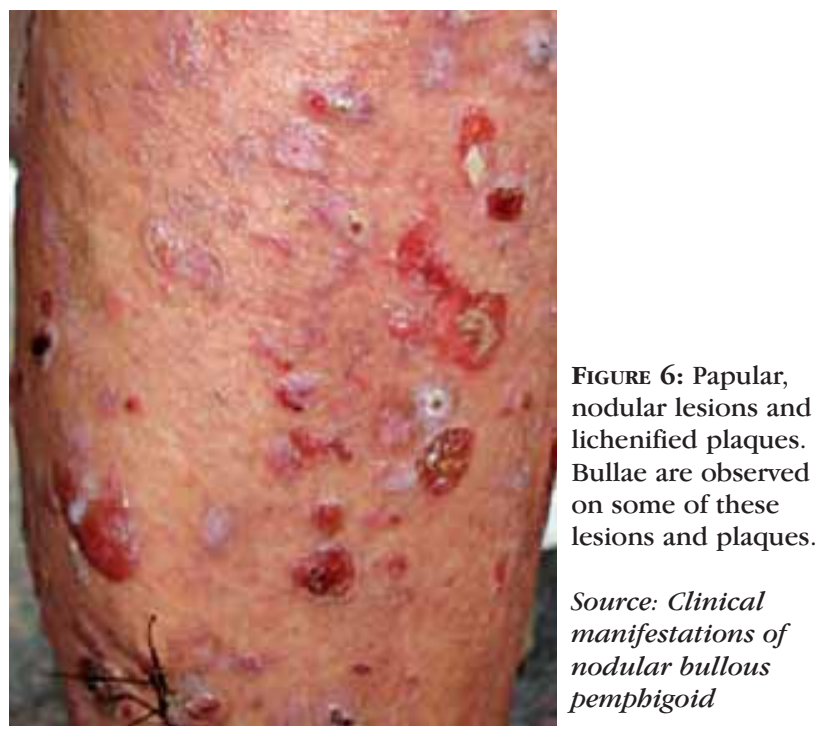

and skin lesions (nodules) showed linear, continuous and intense deposition of $\mathrm{C} 3$ in the BMZ. Once BP was diagnosed (drug-induced/ nodular variant) dapsone $(100 \mathrm{mg} /$ day) and prednisone $(0.5 \mathrm{mg} / \mathrm{kg})$ were introduced and captopril was suspended, with improvement of symptoms in three months.

\section{DISCUSSION}

In $\mathrm{BP}$, there is production of autoantibodies (auto-Ab) directed against transmembrane proteins (BP180) and hemidesmosomal plaque (BP230), with subsequent activation of the complement system, recruitment of inflammatory cells (mainly eosinophils and neutrophils) and formation of subepidermal bulla. The most important antigen (Ag) of the hemidesmosome is the NC16A extracellular domain of the BP180, located near the basal keratinocyte plasma membrane, with cleavage occurring in the upper lamina lucida (LL). ${ }^{1,2,3}$

The auto-Ab are IgE and IgG, especially IgG4. ${ }^{2,4}$ DIF revealed linear IgG (in most cases) and C3 deposition (basically in all patients) in the BMZ. IIF is positive in $80 \%$ of the cases. Indirect Salt Split Skin (indirect SSS) showed autoantibody deposition on the epidermal side of the cleavage (as the major target $\mathrm{Ag}$ are located in the upper portion of the LL). This method is important to differentiate BP from epidermolysis bullosa acquisita and bullous systemic lupus erythematosus. In these dermatoses, deposition of auto-Ab occurs on the dermal side of the cleavage, since the auto-Ag is type VII collagen, which is located in the sublamina densa. ${ }^{2}$

$\mathrm{BP}$ is rare and has some peculiarities in the population under the age of 70 years. There are studies showing an increased expression of anti-BP180 autoantibodies in these patients. Cases in which BP is more widespread are common, with involvement of the neck and head. Treatment resistance is also common. ${ }^{6,7,8,9}$

Elevated total serum IgE and peripheral eosinophilia are common. ${ }^{4}$

In the three cases reported, we chose the combination of dapsone and systemic corticosteroids due to the inflammatory infiltrate rich in polymorphonuclear cells revealed in the AP examination, with the first patient responding surprisingly well. However, in accordance with evidence of resistance to treatment, the second patient did not respond to treatment and the third patient's improvement was slow and progressive.

The third patient presented papular lesions, nodules and lichenified plaques in addition to bullae, with deposits of $\mathrm{C} 3$ in the BMZ of these lesions. Nodular BP is characterized by pruritic papular and nodular lesions that may precede the appearance of 
blisters, occur alone, or with bullous lesions. For the diagnosis of this variant it is necessary to demonstrate the deposition of immunoreagents in the BMZ by DIF in popular, nodular lesions (which differentiates nodular BP from prurigo simplex, when the nodular variant occurs in the absence of bullae). ${ }^{10,11}$

Treatment of located BP can be based on topical corticosteroids (clobetasol). For cases in which it is widespread, prednisone is usually used in low doses $(0.5 \mathrm{mg} / \mathrm{kg})$, as well as dapsone, tetracycline, erythromycin, minocycline, nicotinamide, azathioprine, methotrexate and mycophenolate mofetil. Intravenous pulse therapy with corticosteroids and intravenous gammaglobulin are reserved for the most severe and refractory cases. ${ }^{1,2,3}$

BP can be triggered by drugs (captopril, enalapril, furosemide, spironolactone, amiodarone, losartan, beta-blocker, ibuprofen, fluoxetine, sulfasalazine, chloroquine, D-penicillamine, ampicillin, cephalexin, ciprofloxacin, nalidixic acid, gabapentin and PUVA). ${ }^{2,3,12}$ Use of drugs must be questioned during anamnesis of all patients. In cases two and three, the patients used losartan potassium and captopril, respectively, which were replaced.

We emphasize the importance of considering the possibility of a diagnosis of BP in patients younger than the age group usually affected by this skin disease. It is fundamental to perform DIF, and possibly indirect SSS, for a differential diagnosis between BP and other subepidermal dermatoses, such as linear IgA dermatosis, dermatitis herpetiformis, inflammatory epidermolysis bullosa acquisita and bullous systemic lupus erythematosus.

\section{REFERENCES}

1. Walsh SR, Hogg D, Mydlarski PR. Bullous Pemphigoid: From Bench to Bedside. Drugs. 2005:65:905-26.

2. Sanchez APG, Aoki V. Dermatoses Bolhosas. In Pires MC, Sittart JAS. Dermatologia na Prática Médica. Ed.Roca 2007. p.369-384.

3. Duarte AA, Cucé LC, Alves RMR. Líquen plano bolhoso x líquen plano penfigóide: relato de um caso. An Bras Dermatol. 1991;66:32-4.

4. Stanley JB. Penfigoide Bolhoso. In: Fitzpatrick TB, Feedberg IM, Katz SI, Eisen AZ, Goldsmith LA, Wolff K, et al. Tratado de Dermatologia. New York: McGraw-Hill 2005. p.666-673.

5. Yancey KB. The pathophysiology of autoimmune blistering diseases. J Clin Invest. 2005; $115: 825-8$

6. Bourdon-Lanoy E, Roujeau JC, Joly P, Guillaume JC, Bernard P, Prost C, et al. Bullous pemphigoid in young patients: a retrospective study of 74 cases. Ann Dermatol Venereol. 2005;132:115-22.

7. Ruocco E, Aurilia A, Simonetti G, Cozzani E, Baroni A, Argenziano G. Bullous pemphigoid: three atypical cases. Acta Derm Venereol. 2002;82:222-3.

8. Dasgeb B, Lee-Bellantoni MS, Phillips TJ. Bullous pemphigoid with atypical presentation. Woudnds. 2005;17:196-200.

9. Eigelshoven S, Bruch-Gerharz D, Enderlein E, Ruzicka T, Büchau AS, Hertl M, et al. Severe progression of a bullous pemphigoid in a young man. Hautarzt. 2006;57:320-2.
10. Cliff S, Holden CA. Pemphigoid nodularis: a report of three cases and review of the literature. Br J Dermatol. 1997;136:398-401.

11. Powell AM, Albert S, Gratian MJ, Bittencourt R, Bhogal BS, Black MM. Pemphigoid nodularis (non-bullous): a clinicopathological study of five cases. Br J Dermatol. 2002;147:343-9.

12. Campbell GAM, Campbell IT, Lemos CMFL, Friedman H. Penfigóide Bolhoso - Um caso induzido por droga. An Bras Dermatol. 1993;68:157-9.

How to cite this article/Como citar este artigo: Zanella RR, Xavier TA, Tebcherani AJ, Aoki V, Sanchez APG. Bullous pemphigoid in younger adults: three case reports. An Bras Dermatol. 2011;86(2):355-8. 